\title{
INFORMATION PROFESSIONALS IN INDUSTRIALISED COUNTRIES
}

\author{
Blaise Cronin*
}

Comunicación presentada a la Reunión Regional sobre Formación de Profesionales de la Información (5-9 marzo 1990, Caracas, Venezuela), organizada por la UNESCO.

\section{Competitive edge}

Organisations compete by being different on one or more of the following dimensions:

- Product range.

- Innovativeness.

- Quality.

- Customisation.

- Proprietary knowledge.

- Scope and focus.

- Cost.

- Image.

In a competitive marketplace, you need to know whether, how and where your rivals can compete. You need intelligence on their strengths, weaknesses and strategic intentions. You have to distinguish between public posture and private purpose. You also need to know the mood of the marketplace; what your consumers need, what they want, what can they afford.

To stay ahead of your competitors you need to know what is possible, as well as what is the case (how real is the threat of a potential new entrant, or substitute product or service?); what might happen in addition to what is happening (this entails issue management, or macro-environmental scanning). Intelligence, broadly defined, widely sourced and integratively managed, is the key: flexible information systems (which foster openness, connectivity and exchange) are the platform for building total intelligence capability within organisations.

\section{Rewriting the rules}

In business, innovation is the ability to do things differently: better or more imaginatively. Not just once, but repeatedly. Successful firms are adaptive organisms, capable of sustainable innovation. And innovation is fuelled by information.

Business is a game. Games have players, and players have strategies and stratagems. There are rules (company law; intellectual property rights; standards, UK.

* Department of Information Science, Strathclyde Business School, University of Strathclyde, Glasgow,

Recibido 17-7-90. 
etc.); there are referees (auditors; regulatory bodies; trade agreements); there are risks (political and financial; entry and exit level barriers to negotiate). Players sometimes break or bend rules: that is not recommended.

Clever players, however, cause the rules to change. Notable innovations (which often involve novel information technology applications) effectively rewrite the rules of the game (think of computerised customer reservation systems in the airline industry; teleordering in the drugs supply or bookselling business; ATMs in banking). Quite simply, they change the way business is conducted.

\section{The smart enterprise}

Information is the primary source of value added in today's firm. This is what Wilmot (1) has to say:

"As labour, in the traditional sense, evaporates in most industries, and capital becomes a globally purchasable commodity, IT [information technology] will become the tool for building competitive organisational capability and stimulating competitive behaviour -along with investment in management. Indeed the computer industry already reflects this with direct labour typically representing only $3 \%$ or so of sales."

Leverage is derived from the effective management of information assets and resources (information technology and systems; information professionals; local and bought-in information goods and services). The role of the information manager is to optimise the configuration and exploitation of those assets; to create as far as possible within the organisation the conditions which nurture creativity; to maximise delivered value. This applies as much in the public as private sector, though the goals, objectives, quality measures and performance indicators will naturally differ.

\section{Asset management}

In standard accounting terms, an organisation's assets are classified as tangible or intangible, current or fixed. For instance, stock-in-hand is a current tangible asset (it could be converted into cash), while a company's fixed tangible assets include its buildings and machinery. Goodwill (brand name value; cachet; pedigree) is an important intangible asset, which can sometimes exceed a company's book value.

What are an organisation's information assets? Take the case of a university. Under current tangible we would include publications (produced by research units, scholars, institutes or the university press) along with courseware (teaching materials used, for example, in open or distance learning programmes). Its fixed current assets would include the library system and campus network. An illustration of an intangible current asset (in information terms) would be the consultancy skills and expertise embodied in the academic staff.

At the next level of recursion, we have the information assets which are to be found in a library/documentation centre. The most obvious example of a current tangible asset is the book stock, while the professional skills and know-how of staff 
(from bibliography through systems design to information analysis) are key intangibles. As with any organisation, premises and plant fall under the rubric fixed tangible. In the case of, say, a national library, statutory legal deposit is a major asset (it creates a product mix of considerable breadth and depth which might not otherwise be achievable).

\section{A new paradigm}

Historically, information work has been defined (in both curricula and practice) as the management of a suite of functions, ranging from acquisition to retrieval. A consequence of this mindset can sometimes be goal displacement: in other words, it may not be clear why a specific function is being performed, how it relates to other functions, or indeed to overall information strategy.

One way round this problem is to recognise that information work is fundamentally concerned with the management of a portfolio of assets. We have identified six generic assets in the context of information work: not all will apply in every case. Property is only an asset if the information centre has control over use and disposal of its space, furnishings and fittings. Heritage items are more likely to turn up in the context of an archive or research library than in the technical information centre of an oil company.

The significance of the IT/IS (information technology/information systems) asset base will also vary: where you have a large sunk investment in computer and telecommunications systems, the scope for moving into facilities management, leasing, third party network management, IT skills training and related areas is potentially high.

A major, often undervalued, asset is the mix of professional and technical skills possessed by the information workforce. The information manager will want to be sure that such skills are fully developed and effectively deployed. A leading-edge information service may be strategically placed to offer advice, training and support to other sections of the parent organisation or external markets, thereby consolidating its reputation and position.

A simple matrix can be used to identify different ways of managing your information assets. The range of options (which are not mutually exclusive) includes outright disposal (selling the letters of Borges to a US university for a princely sum), through franchising (allowing a third party vendor to market government data sets) to contracting out (buying in a specialised information service from a commercial supplier, thereby eliminating the fixed cost component).

\section{Transparency and opacity}

Assets can have latent value. One of the tasks of the information manager is to activate latent value. What matters in most organisations is value-in-use. Value may go unrecognised for a variety of reasons: a connection may not be made between an event and a particular parcel of information (the final piece of the jig saw); significant variables and relationships may be masked by the volume of data at hand (cognitive overload), or the inappropriateness of the packaging. In some 
cases, lack of structure may be the problem; in others fondness for structure may actually result in myopia or lost opportunity (Swanson (2) has described cases of logically related but non-interconnecting literature sets).

How can value loss be reduced? Presumably by encouraging greater use of existing information systems and services; by increasing rates of participation. Systems (social and mechanistic) can be enchantingly simple or frustratingly complex to use. Information systems are no exception. Use is impaired by jargon (command languages), design complexity (think of classification schema, academic libraries), rites of passage (determining an individual's eligibility for a password), bureaucracy (accessing government archives or data sets), tariff structures (in the online database industry), lack of standards (in the cataloguing, labelling and exchange of materials).

The primary and secondary characteristics, along with the conditions and effects of both opaque and transparent systems are shown in Table 1. This Table constitutes a simple, but effective diagnostic tool for local application. Open (transparent) systems should have clear structure, a paucity of rules and necessitate few media transformations. Does your system meet these criteria? How does it compare with other, similar systems? Opaque (closed) systems, on the other hand, are characterised by a lack of structural clarity (navigation is not easy), excessive regulation and multiple media transformation (the same piece of information is processed in different ways, formats or media).

Table 1

Transparent and opaque systems

\begin{tabular}{lll}
\hline & Transparent systems & Opaque systems \\
\hline Primary characteristic & Openness & Closure \\
Secondary characteristics & Standards & . Local idioms \\
& Equal access & Elitism \\
& Disclosure & Suppression \\
Conditions & Clear structure & Confusing structure \\
& Few rules & Excessive regulation \\
& Few media transformations & Many media transformations \\
Effects & Accountability & Fudging \\
& Effective interaction & Muddling through \\
& High skills transfer & Low skills transfer \\
& Widespread adoption & Limited adoption \\
\hline
\end{tabular}

\section{Total quality}

The concept of Total Quality has been widely trumpeted in both manufacturing and service industries, and may be defined as follows (3):

"The company that focuses on quality grows closer to its customers and becomes aware of where it needs to improve. The outcome is that customers get what they 
really want and not what the supplier thinks they should have... Total Quality is a means of achieving a cultural revolution that brings home to everyone that, ultimately, no errors will be accepted in supplying the specified product or service.»

There are signs that the information profession may be vaguely aware of the concept. Until recently, though, Total Quality has been noticeable by its absence from both the professional literature and the world of professional practice. Budgetary pressures, demands for accountability and the rising costs of providing information services have thrown quality issues into relief. Can quality be measured? What techniques and indicators are available? What does quality assurance mean in the context of information management? How can customer satisfaction rates be monitored?

Numerous studies have demonstrated the inadequacy of public sector information and reference service, in spite of growing professionalisation. Online vendors have not yet succeeded in penetrating the lay market: most online searches are still mediated by members of the information priesthood. The electronic information industry exhibits the classic features of an anti-service culture: systems lacking conviviality; table d'hote menus rather than a la carte service.

Obduracy and arrogance on the parts of designers and vendors, fiscal pressures and vested interest have combined to retard the rate of innovation. The result? Disaffected users and sub-optimal exploitation of valuable information assets.

\section{Total information}

Total Quality depends on Total Information: information on risks, liabilities, limitations, behaviours and volatilities... of situations, physical and social structures, materials, services and people. It is as true of constructing an off-shore oil rig, conducting a laboratory experiment, or offering a medical diagnosis as of operating a current awareness service. Total relevant information is what clients require. Where and how it is sourced, selected and sanitised need not be a matter of concern. What matters is that it should be timely, validated and pertinent. Quality assurance is what matters.

\section{Information management and quality assurance}

The health of a nation (reflected in morbidity and mortality rates) is a key quality of life indicator. Today, quality of health (and by extension, quality of life) increasingly depends on the quality of information management.

The National Health Service (NHS) in the UK is a complex, multi-billion pound «business». It is also the largest employer in Western Europe. Health care is not simply about illnesses, drugs and hospital beds: it is about the management of information (patient-related information, hospital activity analyses, epidemiological data, technical news, clinical trial data, expenditure patterns, remission rates, etc.).

With rising public demand and treatment costs, the need for effective, efficient and economic management is paramount. The proposed restructuring of the NHS 
has resulted in formal recognition of the importance of information management at all levels (4). Consider the four domains below:

- Resource Management: comparative information for clinicians whose decisions about treatment commit considerable sums of money (what is the best, most cost-effective treatment for a particular condition?). Health Authorities will need aggregate information to identify priorities and trends, assess local health requirements, and compare hospital performance.

- Medical Audit: there is a need for better information about the outcomes of various treatments to enable clinicians to compare and evaluate their own decisions.

- General Medical Practices: general practitioners (community doctors) require faster and more accurate information to improve patient service (computerisation of medical records; out-patient booking systems; introduction of smart cards; use of laptop computers; online access to medical information services, etc.).

- Trading Information: in the proposed restructuring, Health Authorities and the larger general practices (groups of community doctors) become budget holders for satisfying the health needs of their local populations (typically 250,000 people) and for negotiating contracts with hospitals to provide such services. They will, therefore, need better budgeting, monitoring and forecasting tools; in other words, better management information and decision support systems.

The importance of information management is clearly grasped (5):

"The NHS is an information intensive organisation, being dependent on patient and clinical information for treatment, and organisational and management information for organising its efficient running.»

The recognition goes beyond rhetoric: the NHS Training Authorities has launched an ambitious national programme in Information Management and Technology (IMT) to ensure that clinical, nursing, administrative and managerial staff are aware of current thinking and practice.

\section{Public administration and information management}

Information management awareness is not confined to the health sector. Since 1984, H M Treasury has been spearheading a major initiative to identify ways of getting better value for money from government information resources (6). Studies have since been conducted in a number of departments using the soft systems approach, and early results are promising.

None of this is particularly novel: information resources management (IRM) grew out of US Federal Government policy in the mid-1970s, was taken on board by the corporate sector in the early 1980s and the academic community in the mid80 s (witness the emergence of IAIMS - Integrated Academic Information Management Systems). The point is that this wave of information awareness has implications for the labour market: demand for information professionals and information managers is buoyant in the public, private and voluntary sectors. This, in turn, has supply side implications: what kinds of educational programmes and curricula are required? 


\section{The information industry}

Demand for information skills is widespread and increasing. The information industry in the UK accounts for roughly $7.5 \%$ of GDP. It is a growth industry, comprising a relatively small number of multinational corporations and a plethora of small, specialist companies. Table 2, taken from the most recent survey of the UK information industry (7) shows the information subsidiaries of some of the major players. Having a financially robust parent company is very important in a sector where profitability is rarely achieved overnight.

Of course, not all of those employed in the industry are information workers, but projections for 1995 (8) suggest that information occupations within the information industry will account for more than 4.36 million jobs. These figures are achieved by using a very broad definition of information work. If information workers are defined in terms of the occupational slots classically filled by graduates of information studies programmes (or in terms of the membership registers of the various professional bodies), the figures will be much smaller, in the range 27,000 to $164-328,000(9)$.

Where will the jobs be found? Some idea can be had from Table 3 which shows the latest available turnover figures for the different sectors of the industry, ranging from library automation with $£ 23$ million to Company and Stock Market Information (Peuters returns included) with a massive $£ 1$ billion plus. The industry is difficult to define with any degree of precision; accurate figures on its dimensions are hard to come by; its workforce is heterogeneous in the extreme (in terms of disciplinary and professional backgrounds). However, it is absorbing a growing number of graduates from information studies programmes and is likely to constitute a major source of future employment. But the schools of information studies and information management will have to tailor their programmes and output to the particular needs of this market.

The following quotation taken from a 1989 British Library report, Curriculum development in information science to meet the needs of the information industries in the 1990s, highlights the changes which will be required (10):

"The Department of Information Science of Strathclyde University's Business School... has undertaken a dynamic and ongoing process to publicise the existence of its course objectives and content, with the aim of increasing the size and potential of the pool of applicants. From this enlarged 'cohort' there is greater possibility of selecting people who will have the personality characteristics, enthusiasm and drive to master the areas of knowledge needed to perform in the information industry. Strathclyde's links between business and information science and management, and its determination to devote itself to producing appropriate manpower for the information industry have challenged all the other library and information studies schools in the country. It is no longer possible to say that such things are a good idea but not practicable.»

\section{Roles and responsibilities}

The information profession of the 1990s will comprise three main groups: developers, constructors and craftsmen (see Figure 1). Developers will be responsible 
Table 2

A comparison of turnovers

(1988 figures unless indicated otherwise)

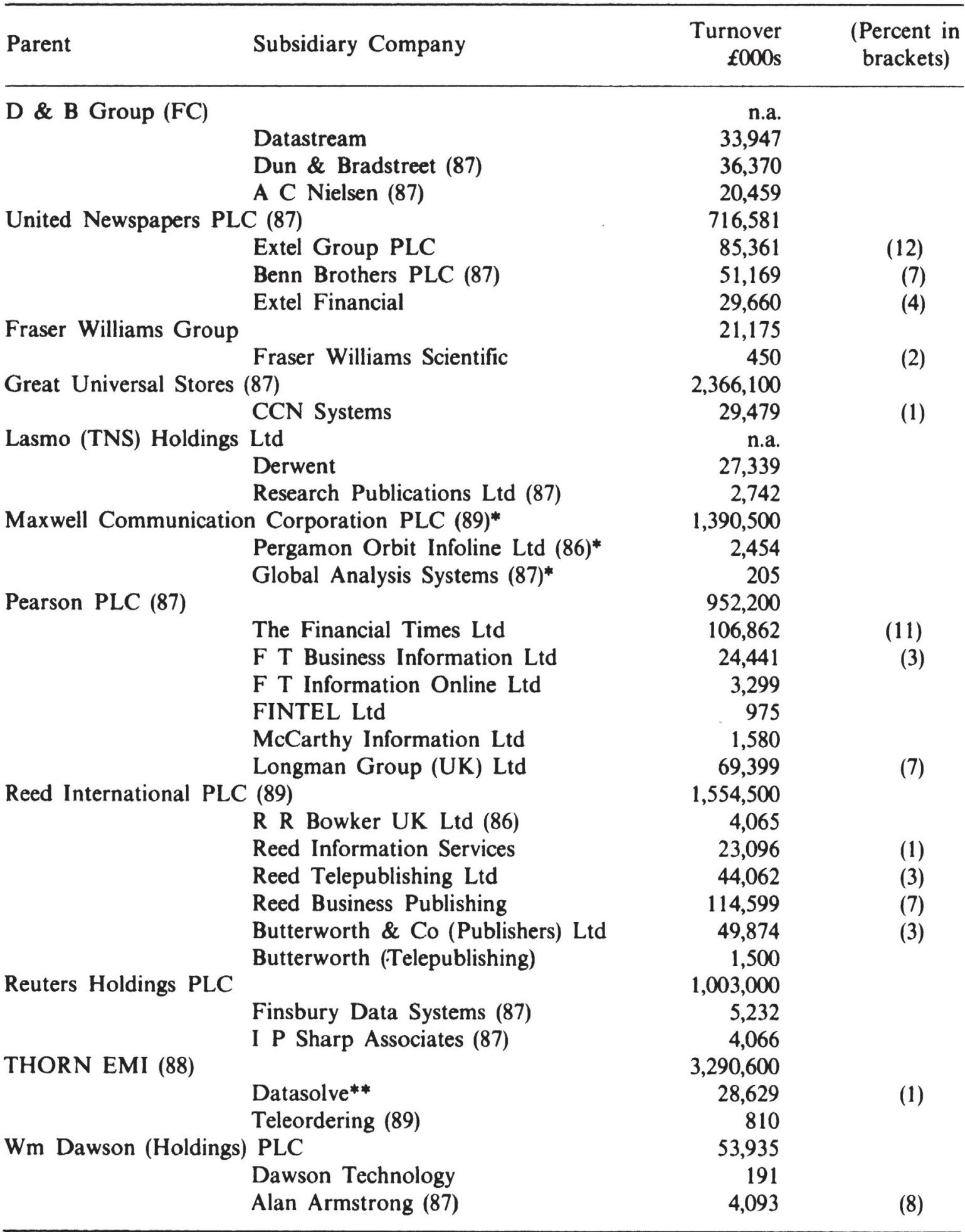

* Not parent and subsidiary companies, but included purely for comparison.

* No longer trading. 
Table 3

Summary Table - Performance

\begin{tabular}{lccc}
\hline Sector & $\begin{array}{c}\text { Combined } \\
\text { Turnover } \\
\text { Latest year } \\
\text { £Million }\end{array}$ & $\begin{array}{c}\text { Combined } \\
\text { Pre-tax } \\
\text { Profit/Loss } \\
\text { fMillion }\end{array}$ & $\begin{array}{c}\text { Pre-tax } \\
\text { Profit/Loss } \\
\text { over Turnover } \\
\%\end{array}$ \\
\hline Library Automation & 23.00 & 0.27 & 1 \\
Bibliographic Agencies & 10.00 & 2.42 & 24 \\
Smaller Database Producers & 35.00 & 4.77 & 14 \\
Specialist Sofware Houses, etc. & 14.00 & -0.32 & - \\
Hosts & 9.00 & $<-0.30$ & 8 \\
Gateways (VANs) & 94.00 & 7.84 & 5 \\
Market Research & 230.00 & 11.62 & 0 \\
News & 36.00 & 0.15 & 22 \\
Credit Reporting & 80.00 & 17.38 & 19 \\
Company \& Stock Market without & 124.00 & 23.54 & 22 \\
$\quad$ Reuters & $1,103.00$ & 237.95 & 16 \\
Company \& Stock Market with & 64.00 & 9.99 & 5 \\
$\quad$ Reuters & 7.00 & 0.34 & - \\
Business Statistics, etc. & 3.00 & -0.16 & \\
Conference Organisers, etc. & & & \\
Specialist CD-ROM houses & & & \\
\hline
\end{tabular}

Figure 1

Roles and Responsabilities

\begin{tabular}{|l|l|l|l|}
\hline DEVELOPERS \\
\hline CONSTRUCTORS \\
\hline CRAFTSMEN
\end{tabular}

\begin{tabular}{|c|c|}
\hline $\begin{array}{l}\text { PROFESSIONAL } \\
\text { ROLE }\end{array}$ & $\begin{array}{c}\text { PRIMARY } \\
\text { FOCUS }\end{array}$ \\
\hline
\end{tabular}

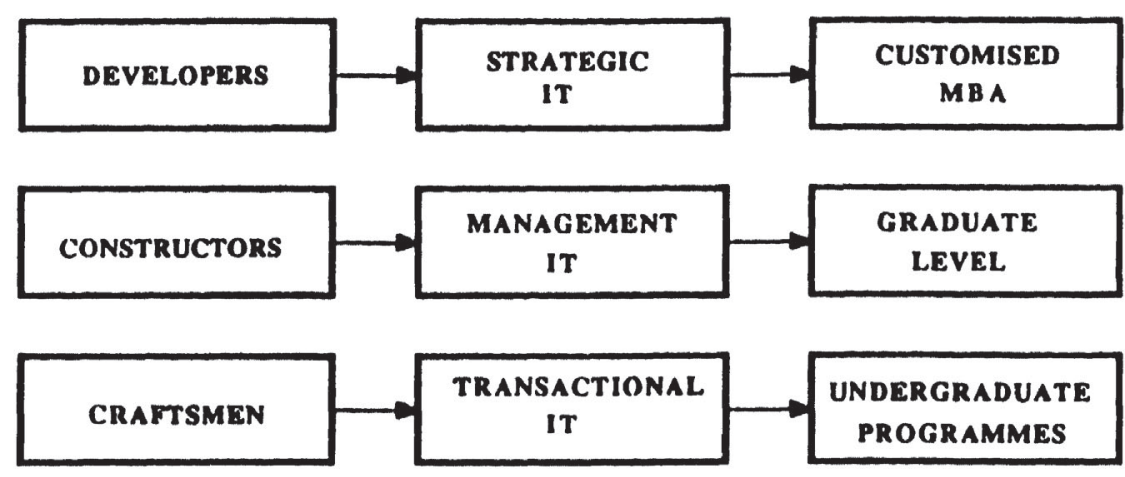


for organisation-wide information investment and management, and for driving IS/IT strategy. These individuals will be hybrid managers, combining business knowledge and experience with substantial IT know-how. Base level concepts and skills may be acquired in some cases through existing educational programmes, but the majority will develop their capabilities in the world of work, supplemented by high-level strategic planning courses delivered by commercial training organisations (major consulting companies, for example) or business schools, offering customised or streamed MBA programmes.

At the next level are the constructors, whose task it is to translate the strategic vision into actuality. These individuals will have the in-depth technical skills to create a systems environment with requisite functionality. Specifically, they will be competent in the area of network design and management information systems. Some of the better information studies programmes are already producing constructors.

Level three is the domain of the craftsman, the traditional output from information studies programmes. The craftsmen are responsible for putting the bricks and mortar in place, ensuring that the systems and services conceived and installed by the developers and constructors actually deliver the goods. Until now, this area has represented the heartland for the graduates of information studies programmes. But will that continue to be the case in the 1990s?

\section{References}

1. WILMOT, R. W. Organisational issues and I.T., A management briefing prepared from a presentation to IBM CUA conference, 21 April 1988, London: Oasis, 1988.

2. SWANSON, D. R. A second example of mutually isolated medical literatures related by implicit, unnoticed connection, Journal of the American Society for Information Science, 40 (6), 432-435, 1989.

3. Total quality: achieving competitive advantage, Middlesbrough: Price Waterhouse, 1988.

4. HILLS, P. The national strategic framework for NHS information management in England, Aslib Proceedings, 41 (19), 275-278, 1989.

5. SCRIVENS, E. Policy, power and information technology in the National Health Services, Bath University: Centre for the Analysis of Social Policy, 1985.

6. SANGWAY, D. Government approach to information management, Aslib Proceedings, 41 (5), 179-187, 1989.

7. The UK information industry: a financial survey, London: Jordans, 1989.

8. ANGELL, C. Information, new technology and manpower, London: British Library, 1987.

9. CAWKELL, A. E. Job indentification and education for the new information profession, in Brittain, M. (ed.). Curriculum development in information science to meet the needs of the information industries in the 1990s, London: British Library, 16-22, 1989.

10. ORMEROD, P. Meeting manpower needs for marketing online business databases, in Brittain, M. (ed.). Curriculum development in information science to meet the needs of the information industries in the 1990s, London: British Library, 23-30, 1989.

\section{Additional suggested reading}

1. CRONIN, B.: DAVENPORT, E. Post-professionalism: transforming the information heart land, London: Taylor Graham, 1988.

2. CRONIN, B.; DAVENPORT, E. Elements of information management, New Jersey: Scarecrow (to appear 1990). 